\title{
SISTEM INFORMASI PELAYANAN BARANG DAN JASA BERBASIS DESKTOP PADA SALON IRFAN
}

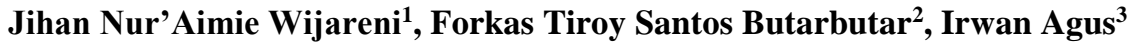 \\ ${ }^{1,2,3}$ Universitas Indraprasta PGRI \\ Jalan Raya Tengah Nomor 80, Kelurahan Gedong, Pasar Rebo, Jakarta Timur \\ 1jihanaimie@gmail.com, ${ }^{2} \mathrm{ftsb} 43 \mathrm{dharma} @$ gmail.com, ${ }^{3}$ irwan.agus08@yahoo.com
}

\begin{abstract}
ABSTRAK
Pengolahan data pada Salon Irfan masih dilakukan secara konvensional. Sistem pengolahan data masih dilakukan secara konvensional sangat menyulitkan pada saat pencarian data, karena dalam pencatatan data masih menggunakan satu pembukuan transaksi dan agar tidak terjadi kesalahan dalam mengolah data tersebut maka membutuhkan ketelitian yang lebih untuk merancang dan mengimplementasikan sistem informasi pelayanan barang dan jasa yang efektif dan efisien pada Salon Irfan. Dalam penulisan penelitian ini, peneliti akan menggunakan metode kualitatif dan menggunakan model waterfall sebagai metode pengembangan sistem . Hasil dari penelitian ini adalah adanya suatu sistem informasi berbasis desktop dengan menggunakan Java NetBeans 8.2 dan database MySQL tool XAMPP 7.2.34 yang dapat memberikan kelancaran dalam sistem informasi pelayanan barang dan jasa pada Salon Irfan.
\end{abstract}

Kata Kunci: Sistem Informasi, Pelayanan Barang dan Jasa, Salon.

\section{ABSTRACT}

Data processing at Salon Irfan is still done conventionally. The data processing system is still carried out conventionally, it is very difficult when searching for data, because in recording data it still uses one transaction book and so that there is no error in processing the data requires more accuracy. to design and implement an effective and efficient information system for goods and services at Salon Irfan. In writing this research, researchers will use qualitative methods and use the waterfall model as a system development method. The result of this research is the existence of a desktop-based information system using Java NetBeans 8.2 and MySQL database tool XAMPP 7.2.34 which can provide a smooth system of information services for goods and services at Salon Irfan.

Key Word: Information Systems, Service of Goods and Services, Salon.

\section{PENDAHULUAN}

Perkembangan bisnis pada saat ini semakin pesat dan memiliki banyak pesaing dari berbagai pelaku usaha. Inovasi dan kreatifitas para pelaku usaha dapat berpengaruh dalam memenangkan persaingan. Penggunaan teknologi adalah sarana yang sangat berpengaruh dalam meningkatkan keberhasilan aktivitas bisnis. Hampir semua kegiatan dalam bidang usaha pada saat ini dilakukan dengan menggunakan teknologi dengan tujuan utama yaitu untuk mencari keuntungan, kelanjutan usaha, serta pertumbuhan dan perkembangan usaha.

Salon Irfan merupakan suatu bidang usaha yang bergerak dalam pelayanan barang dan jasa kecantikan yang melakukan aktivitas bisnisnya masih secara konvensional. Pengolahan data yang dilakukan dengan pencatatan data didalam satu pembukuan transaksi yang sangat menyulitkan pada saat pencarian data dan agar tidak terjadi kesalahan dalam mengolah data tersebut membutuhkan ketelitian yang lebih, maka akan dibuat sebuah sistem informasi untuk Salon Irfan yang dapat membantu dalam pengolahan data, pencarian data, dan mempermudah saat melakukan transaksi, sehingga dapat membantu meningkatkan layanan salon dan aktivitas bisnis serta memberikan kenyamanan bagi pelanggan.

Sistem merupakan sekumpulan elemen yang bekerja sama dalam suatu kesatuan untuk melaksanakan suatu fungsi yang berguna (Saputro, 2015).

Informasi merupakan sebuah proses pengambilan keputusan dengan menggunakan data yang telah diklasifikasikan atau diinterpretasikan (Saputro, 2015). Sistem informasi merupakan suatu sistem pada yang mempertemukan kebutuhan pengolahan transaksi harian untuk mendukung fungsi operasi organisasi dengan menyediakan informasi dan laporan kegiatan yang diperlukan 
dari suatu organisasi (Antonio, 2012). Pelayanan merupakan suatu yang menghasilkan kualitas pelayanan bagi pelanggan (Gultom, 2014).

Barang adalah segala sesuatu yang biasanya dapat ditawarkan kepada konsumen baik berwujud maupun tidak berwujud yang diterima oleh pembeli (Nurhayati, 2018). Sistem persediaan barang adalah suatu sistem untuk mengelola persediaan barang di Gudang (Nawang, 2017). Jasa adalah sesuatu yang berupa pelayanan dari seseorang kepada orang lain yang bersifat secara esensial atau tidak berwujud fisik (Gultom, 2014). Diagram Alir Data merupakan alat bantu yang dapat digunakan untuk menggambarkan aliran data informasi (Zulfiandri, 2017).

Entity Relationship Diagram (ERD) merupakan teknik model pendekatan yang menggambarkan atau menyatakan hubungan suatu model (Fridayanthie, 2016). NetBeans adalah sebuah perangkat lunak dikembangkan untuk pemogram, mengompilasi, mencari kesalahan dan menyebarkan program serta dapat berjalan di berbagai jenis sistem operasi dan platform (Ramadhani, 2021).

MySQL merupakan sebuah program database server yang mampu menerima dan mengirimkan datanya dengan menggunakan perintah standar SQL (Turaina, 2016).

\section{METODE PENELITIAN}

Metode yang digunakan dalam penelitian ini yaitu metode kualitatif karena data yang didapatkan akan lebih lengkap, lebih mendalam, kredibel, dan bermakna, sehingga tujuan penelitian dapat dicapai. Desain penelitian kualitatif ini adalah perencanaan kegiatan yang dilakukan dalam tahap ini adalah sebagai berikut yaitu, analisa kebutuhan, desain sistem dan perangkat lunak, implementasi dan pengujian unit, integrasi dan pengujian sistem, operasi dan pemeliharaan sistem. Pelaksanaan pada tahap ini peneliti sebagai pelaksana penelitian sekaligus sebagai human instrument mencari informasi data. Analisis data dilakukan setelah peneliti melakukan wawancara mendalam terhadap bapak Irfan selaku pemilik Salon Irfan. Evaluasi semua data Salon Irfan yang telah dianalisis kemudian dievaluasi sehingga diketahui kebutuhan.

Langkah-langkah pengembangan sistem untuk merancang sebuah sistem pengembangan dalam suatu penelitian ini menggunakan model SDLC (Software Development Life Cycle). Model SDLC yang dipakai dalam penelitian ini adalah model Waterfall. Waterfall Model atau Classic Life Cicle merupakan model yang paling banyak dipakai dalam Software Enginnering (SE). Waterfall karena tahap demi tahap yang harus dilalui menunggu selesainya tahap sebelumnya dan berjalan berurutan (Andriansyah, 2016). Tahap-tahap dalam sebuah pengembangan model waterfall adalah sebagai berikut:

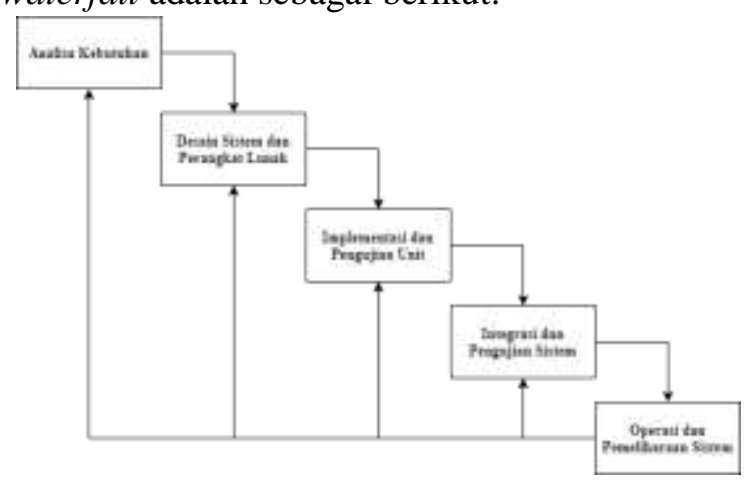

Gambar 1. Model Waterfall

Sumber: (Sommerville, 2016)

\section{HASIL PEMBAHASAN}

Analisa permasalahan yang ada pada Salon Irfan adalah sulitnya membuat data transaksi yang mencangkup pendataan persediaan stok barang karena sering terjadi kehabisan stok barang yang membuat pelanggan kecewa. Dalam pencatatan data barang dan sering mengalami kesalahan menghitung dan kurang keakuratan dalam perhitungan sehingga dapat menimbulkan kekeliruan dalam sisa barang. Sering tejadinya ketidaksamaan antara pelayanan jasa yang dipilih dengan bukti transaksi yang dilakukan pelanggan pada saat melakukan transaksi.

Mencari alternatif penyelesaian masalah sangat dibutuhkan guna membangun operasional Salon Irfan agar dapat meningkatkan perkembangan ke arah yang lebih baik lagi dari sebelumnya. Diperlukan adanya suatu sistem yang terkomputerisasi dan dapat mengganti sistem lama untuk pengolahan data pada Salon Irfan agar dapat mempermudah pekerjaan admin dan karyawan, tidak memerlukan banyak waktu dan tenaga dalam pembuatan laporan yang diserahkan kepada pemilik Salon Irfan, dan laporan bisa dibuat kapan saja jika diperlukan. Dengan adanya sistem yang telah terkomputerisasi diharapkan dapat meminimalisasi kesalahan perhitungan dan kurang keakuratan yang terjadi pada sistem lama.

Aturan bisnis pada Salon Irfan adalah pelanggan datang sebagai anggota akan mendapatkan potongan harga $10 \%$. Pelanggan datang sebagai umum tidak mendapatkan potongan harga. 
Pelanggan memilih layanan barang dan jasa sesuai keinginannya. Admin melakukan pendataan pelanggan yang sudah memilih layanan barang dan jasa. Karyawan melayani pelanggan sesuai dengan barang dan jasa yang dipilih. Admin memberikan laporan ke pihak salon.

Berikut ini adalah diagram konteks sistem informasi pelayanan barang dan jasa pada Salon Irfan:

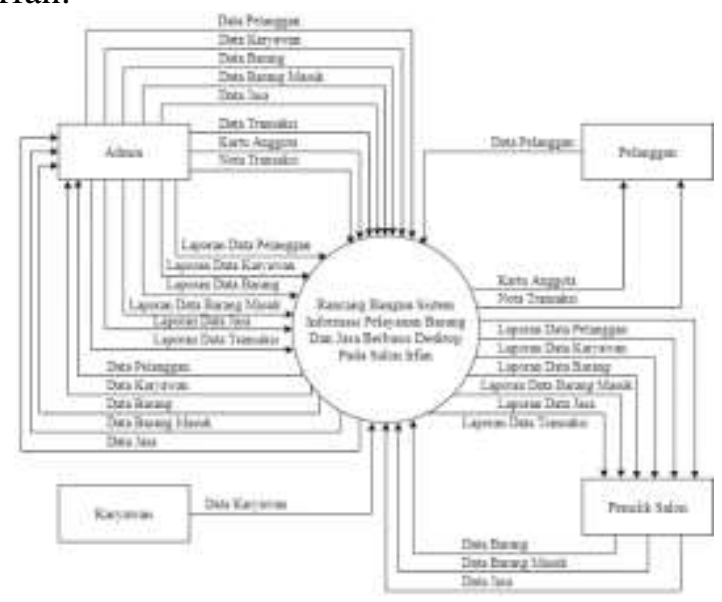

Gambar 2. Diagram Konteks

Berikut ini adalah ERD sistem informasi pelayanan barang dan jasa pada Salon Irfan:

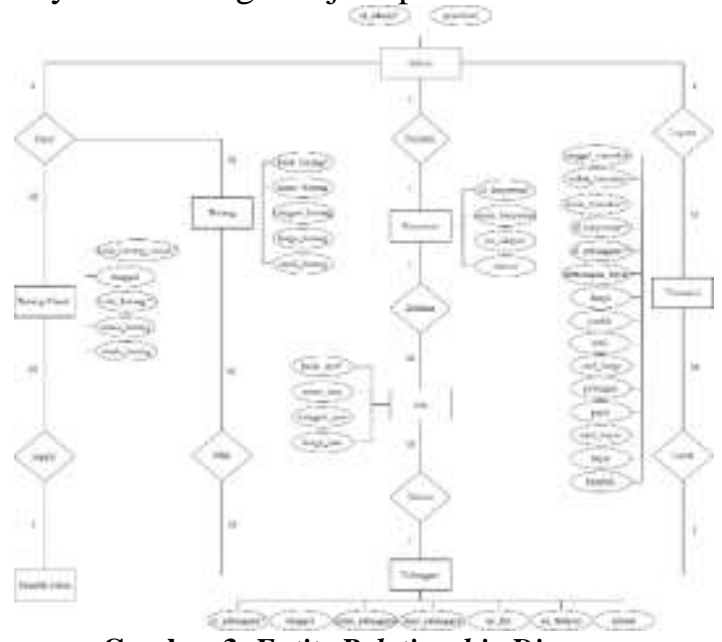

Gambar 3. Entity Relationship Diagram

Berikut merupakan tampilan layar yang di hasilkan sebagai berikut:

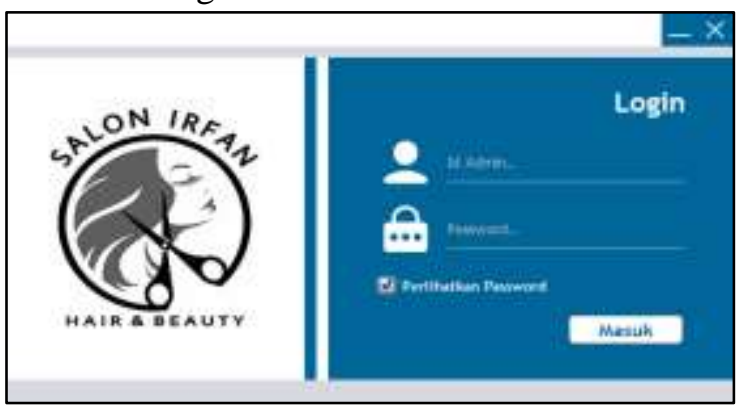

Gambar 4. Tampilan Login
Tampilan login menggunakan id admin dan kata kunci sebelum kita memasuki atau menjalan program, sehingga kerahasiaan terjaga dan orang yang tidak berhak tidak dapat menjalankan program ini.

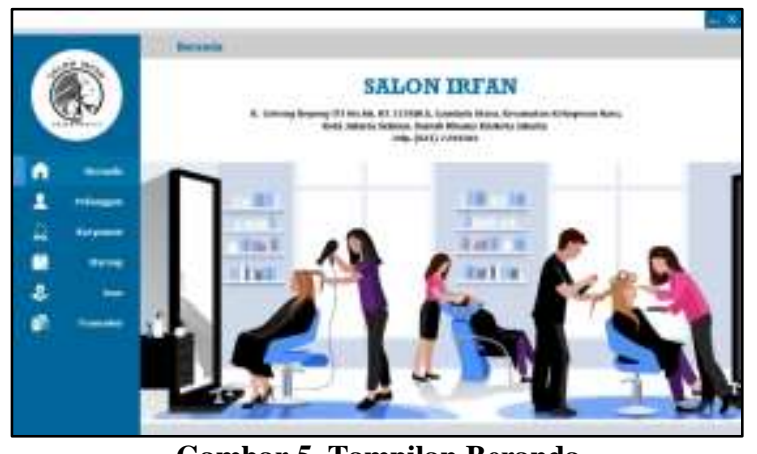

Layar ini menampilkan tampilan menu utama pada sistem informasi pelayanan barang dan jasa yaitu beranda. Pada layar beranda tersedia pilihan menu navigation bar yang dapat dipilih sesuai dengan kebutuhan admin saat menjalankan sistem informasi ini.

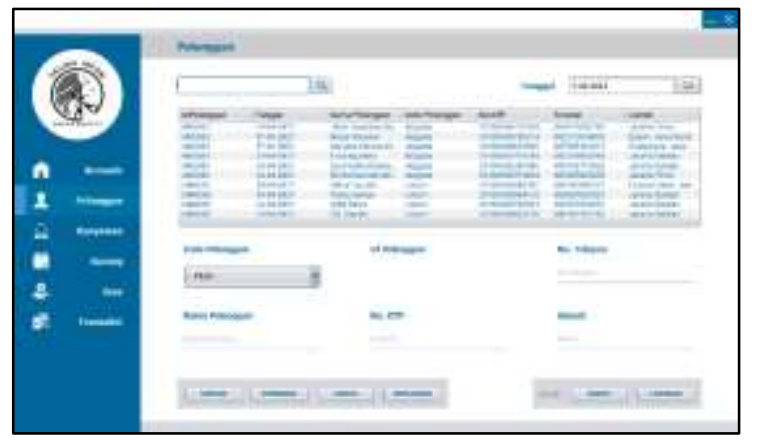

Gambar 6. Tampilan Menu Pelanggan

Layar ini menampilkan tampilan menu data pelanggan. Admin dapat melakukan pengolahan data pelanggan, dapat mencari data pelanggan yang diinginkan, dan dapat mencetak kartu anggota, serta mencetak laporan data pelanggan.

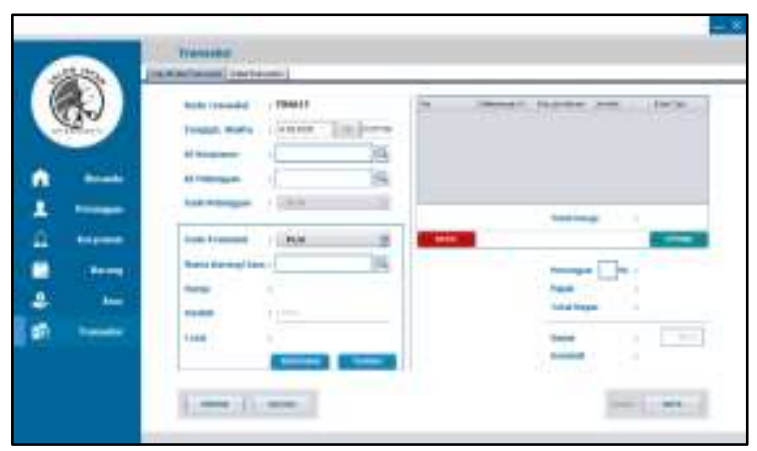

Gambar 7. Tampilan Menu Transaksi

Layar ini menampilkan tampilan menu transaksi. Admin dapat melakukan pengolahan data transaksi, menyediakan tombol menu pencarian 
data karyawan, pelanggan, barang, dan jasa yang dapat dipilih sesuai transaksi yang akan dilakukan, dan dapat mencetak nota transaksi.

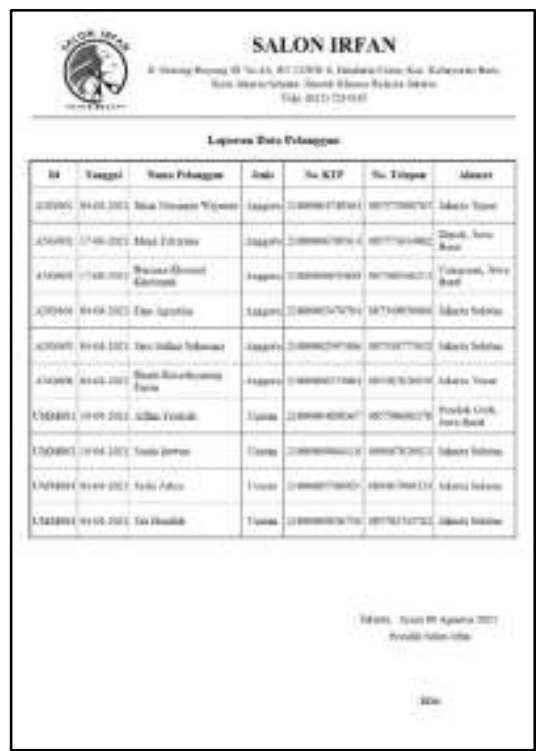

Gambar 8. Tampilan Laporan Data Pelanggan

Layar ini menampilkan menu cetak laporan yang digunakan untuk mencetak laporan data pelanggan.

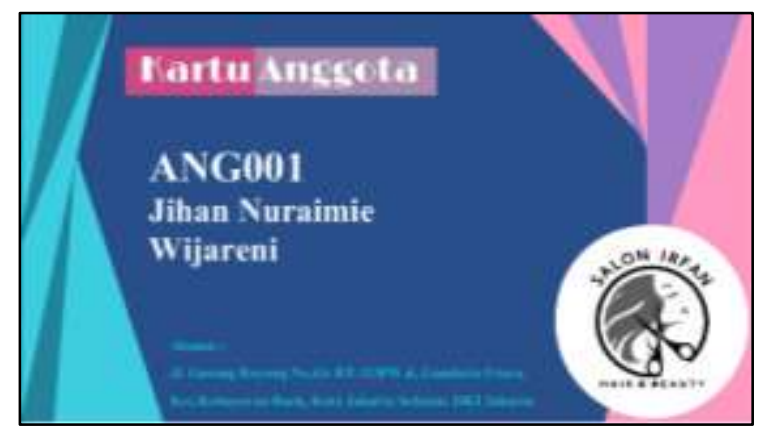

Gambar 9. Tampilan Kartu Angota

Layar ini menampilkan menu cetak kartu yang digunakan untuk mencetak kartu anggota.

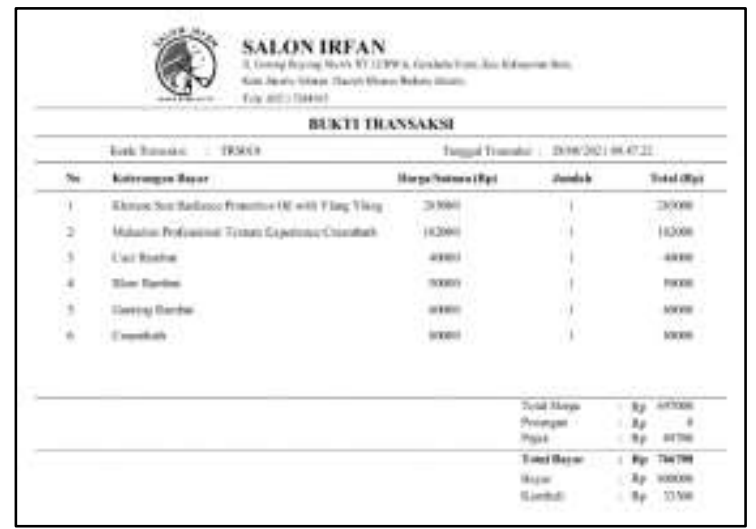

Gambar 10. Tampilan Nota Transaksi

Layar ini menampilkan menu cetak nota yang digunakan untuk mencetak nota transaksi.

\section{SIMPULAN DAN SARAN}

Dengan dibuatnya sistem informasi pelayanan barang dan jasa pada Salon Irfan, semua kegiatan yang berhubungan dengan pelayanan barang dan jasa dapat berjalan dengan baik dan lancar.

Adapun simpulan sistem informasi pelayanan barang dan jasa ini adalah sistem pendataan pelayanan barang dan jasa pada Salon Irfan lebih efektif, karena pengolahan data sistem informasi ini sudah terkomputerisasi. Data dapat tersimpan dengan aman, karena menggunakan database yang memiliki enkripsi password dan sistem informasi ini memudahkan dalam pencarian data pelanggan dan data barang, sehingga tidak terjadinya kesalahan pada saat pengambilan data.

Sistem informasi pelayanan barang dan jasa pada Salon Irfan sudah terkomputerisasi, sehingga dapat memudahkan dalam pembuatan laporan transaksi yang cepat dan akurat, serta dapat meminimalisir ketidaksamaan antara pencatatan transaksi dengan laporan data transaksi. Sistem informasi pelayanan barang dan jasa pada Salon Irfan telah terkomputerisasi, maka dapat meminimalisir kesalahan pengguna atau pemakai pada saat melakukan pengolahan data pelayanan barang dan jasa yang dapat terjadi jika sistem masih dijalankan secara konvensional, sehingga membuat karyawan dan pelanggan menjadi nyaman.

Saran dari penulis atas hasil penelitian yang dilakukan pada Salon Irfan adalah sistem informasi pelayanan barang dan jasa pada Salon Irfan dapat dikembangkan kembali dalam hal desain atau penambahan database data pelanggan, data karyawan, data barang, data barang masuk, data jasa, dan data transaksi sesuai kebutuhan salon. Sistem informasi pelayanan barang dan jasa pada Salon Irfan harus didukung dengan sistem yang disiplin dan agar peraturan yang sesuai dengan ketetapan bersama dapat berjalan dengan seharusnya. Ketelitian merupakan salah satu hal utama dalam penggunaan dan menjalankan sistem informasi, sehingga disarankan untuk pengguna atau pemakai sistem informasi pelayanan barang dan jasa ini harus teliti pada saat melakukan pengolahan data pelayanan barang dan jasa agar tidak terjadi kesalahan yang tidak diinginkan.

\section{DAFTAR PUSTAKA}

Andriansyah, D. (2016). Sistem Informasi eProfileSubjek Pajak Pada Kecamatan Kembangan Jakarta Barat Menggunakan Metode Waterfall. 1(1), 1-10. 
http://ejournal-

binainsani.ac.id/index.php/IMBI/article/vie w/149

Antonio, H., \& Safriadi, N. (2012). Rancang Bangun Sistem Informasi Administrasi Informatika (SI-ADIF). Jurnal ELKHA, 4(2), 15.

Fridayanthie, E. W., \& Mahdiati, T. (2016). Rancang Bangun Sistem Informasi Permintaan Atk Berbasis Intranet (Studi Kasus: Kejaksaan Negeri Rangkasbitung). IV(2), 126-138.

Gultom, D., Ginting, P., \& Sembiring, B. (2014). Pengaruh Bauran Pemasaran Jasa dan Kualitas Pelayanan Terhadap Mahasiswa Program Studi Manajemen Fakultas Ekonomi Universitas Muhammadiyah Sumatera Utara. Manajemen Dan Bisnis, 14(01), 21-33.

Nawang, M., Kurniawati, L., \& Duta, D. (2017). Rancang Bangun Sistem Informasi Pengolahan Data Persediaan Barang Berbasis Dekstop Dengan Model. 13(2), 233-238.
Nurhayati, A. N., Josi, A., \& Hutagalung, N. A. (2018). Rancang Bangun Aplikasi Penjualan Dan Pembelian Barang Pada Koperasi Kartika Samara Grawira Prabumulih. Jurnal Teknologi Dan Informasi, 7(2), 13-23. https://doi.org/10.34010/jati.v7i2.490

Ramadhani, R., Niswati, Z., Dewi, N., Nangka, J., Tb, N. C., Barat, K. T., Jagakarsa, K., \& Selatan, J. (2021). Rancangan Aplikasi Pembayaran Kursus Stir Mobil Al ' Fajri Berbasis Java Netbeans. 643-647.

Saputro, R. A. (2015). Rancang Bangun Sistem Informasi. Romney Dan Steinbart, tahun 2016, 7-25.

Sommerville, I. (2016). Software Engineering $G E$. Pearson Australia Pty Limited.

Turaina, R., Gaputra, I., \& Eviza, S. A. V. (2016). Pemesanan Travel Berbasis Sms Gateway Dan Java Netbeans Pada Cv.Ratu Pasaman Travel. 9(1), 1-12.

Zulfiandri, R., \& Mahmud, A. (2017). Sistem Pencatatan Penilaian Rapor Siswa Berdasarkan Kurikulum 2013 ( Studi Kasus MIN Pasar Baru Bintuhan ). 13(1), 36-43. 